\title{
Integration of National Languages through a Global Communication System: Culture Reflection
}

\section{Ysmailova Raikan1 (iD, Kochkonbayeva Sonayim², Zhakaeva Gulsina², Salieva Dinara1, Dyikanbayeva Rita1, Alymbayeva Aisynai'2, Madmarova Zeinegul'2, Adylbekova Bekzada1, Dzheenbaeva Kosmira1}

${ }^{1}$ Department of Social-Humanitarian Disciplines, Osh State University, Osh, Kyrgyzstan

${ }^{2}$ Department of Practical Course of English, Osh State University, Osh, Kyrgyzstan

Email: r.ismailova@yahoo.com

How to cite this paper: Raikan, Y., Sonayim, K., Gulsina, Z., Dinara, S., Rita, D., Aisynai, A., Zeinegul, M., Bekzada, A., \& Kosmira, D. (2020). Integration of National Languages through a Global Communication System: Culture Reflection. Open Journal of Philosophy, 10, 482-493.

https://doi.org/10.4236/ojpp.2020.104034

Received: October 6, 2020

Accepted: November 10, 2020

Published: November 13, 2020

Copyright $\odot 2020$ by author(s) and Scientific Research Publishing Inc. This work is licensed under the Creative Commons Attribution International License (CC BY 4.0).

http://creativecommons.org/licenses/by/4.0/

\begin{abstract}
This article discusses the relationship between language and culture in the global communication system, accompanied by the expansion of the English language, as well as its positive and negative aspects and the development of new communication technologies.
\end{abstract}

\section{Keywords}

Language, Culture Value, Identity, Communication, Information

\section{Introduction}

Language as a key component of ethno-national culture is formed together with the structure of the ethnic group and serves as a source and condition of its life. Therefore, it is impossible to study ethnic characteristics without taking into account language, which is a means of cultural expression. When national languages are integrated through a global communication system, an unfavorable cultural situation may arise. The language of each ethnic group reflects culture, the richness of functional linguistic phenomena. In other words, language serves as a criterion for determining the mentality and knowledge of peoples.

In a globalizing world, the mechanisms and factors influencing national mentality can only be explained in the context of global social experience. In this sense, it is advisable to study language problems in different regions.

Socio-philosophical analysis showed that the policy of linguistic expansion under the guise of introducing new technologies, adopting world culture, and 
any influence leads to cultural, ideological, political and financial dependence.

Technologically and scientifically strong in a globalized world developed countries are trying to change the culture and national thinking of other ethnic groups in accordance with their interests. Therefore, global communication is becoming of great importance in the process of linguistic expansion. Nowadays theories on intercultural communication are different and mostly born in the American academic context (Scannavini, 2013).

The theoretical significance of the study lies in the further expansion and deepening of socio-philosophical knowledge about integration of national languages through global communication and its problems.

\section{Global Communication-Culture Communication}

In today's geopolitical space, in CIS countries the Russian language is replaced by English through a system of global communication. The content of the media process has a certain impact on the emotions, thoughts, individual actions and general activities of a person. Language, which is a powerful tool of thinking, reflects culture and changes the traditional views and way of life of the nation. Language is considered as a necessary condition of human life, that is, through language the subject has the opportunity to express his views and describe objective reality (Humboldt, 1964).

In the context of globalization, efforts are being made to achieve two main goals of transforming the mental stereotypes and behaviors:

1) Exaggeration of the meaning of the English language,

2) Discrediting the national language.

The information revolution, based on the integration of a computer with a telecommunications system, is a radical reorganization of man.

It reduces space and opens boundaries, which allows you to connect to different parts of the globe. In this case, individuals become citizens of the world. Under the influence of the information revolution, the forms of organization of social relations and relations on the space-time continent are undergoing a deep transformation.

A world without borders is losing the concept of territory and becoming new. The process of social interaction will intensify and will face new dynamics. Its negative impact maybe more than positive impact. The advantages brought by English is that people from completely different countries will communicate with one another freely. However, language isn't simply a communication tool, it's additionally the carrier of culture and signs of identity. Faced with the irresistance of English dominance, many non-English speaking countries may feel helpless, and may also feel worried about the culture invasion brought by English dominance. Although the impact brought by English dominance is invisible and intangible, they indeed exist and can't be changed in a short time. Some people even think that cultural imperialism is the continuation of colonial policy, but the means is relatively civilized (Xue \& Zuo, 2013).

Social space is mixed and formed in a single form. All of the above have con- 
tradictions and negative aspects. Because the uniformity of the space of social life means the functioning of a limited number of languages in this region. Back in previous times, languages disappeared, and linguistic processes have changed. In this situation, new languages and peoples were formed and developed. However, in current realities, some languages are threatened with intense disappearance, and the process of emergence of new languages has stopped. This was facilitated by the transition of many peoples to bilingualism (Crystal, 2004).

Every society elaborates codes of communication that are thought of essential for the transmission of information and social and intercultural encountersjust think of oral, written, non verbal and visual communication. Communication is a kind of reflection of society; in fact every language manages to express all the culture devised by a group of people (Combi, 2016). In the context of globalization, the transmission of ethno cultural information from generation to generation takes various forms: works of material and spiritual culture, through a system of symbols and so on. However, linguistic and lexical information plays a key role in such a transition. Ethno cultural information is realized directly and indirectly. With the growth of the media, the transmission of ethno cultural information will decrease. In this case, the family plays an important role, in which the language performs communicative, informational and regulatory, significant functions. A significant function is a function that reveals the main features of the environment. In other words, the language serves as a symbol that defines a group of people. Culture plays an important role in the functioning of the nation, which is a historical community of people based on a single territory, economic activity, political life, language and culture. Symbolic components of culture, especially language, ensure mutual understanding among members of the community; without which an effective solitary life is impossible.

In a multi-ethnic society, several ethnic communicative spaces are formed. Their functional elements are language and ethnic culture. Current trends in globalization stimulate migration and intercultural communication (Akmoldoeva, 1998). This situation has an impact on the language and culture of ethnic groups. Language as a means of communication allows people to form new elements of culture. The media plays an important role in this. This is the main channel for transmitting images, values, elements of ethno culture reflected in the language. The mass media form the communicative space of the ethnic group and enrich the conceptual apparatus due to elements of ethnic culture. As a result, a dialogue of cultures is developing.

\section{Ethnic Language-Culture Values}

The following functions of an ethnic language can be distinguished:

1) Language-a means of defining concepts and symbols belonging to the ethnos;

2) The language ensures communication between all members of the ethnic group; 
3) A person expresses his feelings and emotions in language;

4) Representatives of different generations have the opportunity to learn traditional cultural values through language;

5) People are allowed to develop the spiritual heritage of ethnic groups only through language (Agaev, 1968).

Language as the ethnic carrier actively functions in all spheres of ethnic life, finds reflection in structure and content of communicative interactions of ethnic groups that promotes maintaining integrity of ethnic groups as systems.

Ethnic language-as the specific linguo cultural cognitive phenomenon incorporating and enriching all values of culture. Language as the carrier of cultural values and social knowledge governs social relations. Therefore, language plays an important role in maintaining ethno cultural identity. Individual ideas of an individual, society, freedom, the relations between old and new are transmitted through language. Thanks to these concepts we can learn about the mentality of the nation. Thus, features of ethno cultural space are reflected in the structure of a language. In each language the outlook of ethnic group which is formed under the influence of historical and cultural traditions and norms of communication is expressed. The sociocultural experience reflected in language is integrated into a uniform frame of reference. Language as a means of ethnic identity forms culture, logic, consciousness of ethnic groups, keeps and develops knowledge of people of the world, nature, the person, society, standards of behavior (Smokotin, 2011). At the same time language provides ethno cultural permeability and transfers from generation to generation, maintains transfer of cultural wealth to the next generation. When old traditional norms and means of moral and cultural regulation are broken, language can systematize and keep experience of the previous generations.

Therefore, according to this sign the language has certain impact on formation of ethno cultural identity. The cultural heritage kept in an ethno linguistic picture of the world is also important. Language as a means of strengthening ethno cultural values forms and develops social experience. Through language various systems of society can interact. According to the cultural and cultural features the language designs ethno cultural identity and strengthens socio cultural experience.

National languages are valuable in the registration form of information, are reflected in a semiotics system and are the main form of cognitive activity of the person. Language is also appreciated as a creative source because this phenomenon helps to learn and change the sphere in the course of activity. Grammar, the general structure of the language, its design features, lexical composition are a system of models and categories used in the formation of phrases, as well as a means of analyzing and synthesizing ideas. Each language has its own preconditions for the formation of thinking, according to which the thinking of people, the content and results of their activities are reorganized (Kozlov, 1994b).

Language as an ethno cultural phenomenon reflects all the changes that have occurred at all stages of the historical development of the ethnic group. The 
chronicle of changes in public life in terms of the state of the language and its lexical composition can be reconstructed. Linguistic differences in the definition of subjects and phenomena, situations in objective reality have a semantic character. The bearer of ethnic culture thinks through the images and images prevailing in this culture. The images expressed in words bear the peculiarities of national culture, historical and cultural traditions, national identity and ethnic mentality.

The structural features of language, lexical wealth have a certain influence on the style and direction of intellectual activity, the perception of the world by people, and the evaluation attitude. In other words, the sociocultural experience of the ethnic group is reflected in the diversity of linguistic forms, especially in speech. People learn not only about material reality and the social environment, but also about the world around them through language, which is an instrument of a certain culture.

Language plays an important role in creating and maintaining an ethno cultural image of the world and, as a result, in the construction of ethnic identity. Therefore, in the modern sociocultural space, great attention is paid to the research of the role of language in the formation of the national image of the world. The language not only functions as a single sign system, but is also valuable as a means of coordinating the social development of a person who speaks this language. The world known kyrgyz writer $\mathrm{Ch}$. Aitmatov said that the task of leaving the mother tongue to the next generations belongs to all minority languages. If we cannot compress the language and convey it to the next generation not only the language will disappear, but also the whole nation (Ysmailova et al., 2020).

The systematized sociocultural experience is recorded in the language forms of people's perception of objective reality. Each language defines phenomena and objects in the world around it. Because the material that forms consciousness is a language that has a national identity (Kozlov, 1994a).

Language, known as a means of communication, is not limited to the function of storing information and transmitting it to future generations. Language also has a profound influence on the formation of knowledge about the world.

Language is a means of self-knowledge of one's surroundings and oneself, due to the fact that society and individuals constitute the unity of the individual and community, language is the basis for reflecting and building the "self" ("self") of a person, as well as society as a whole.

Therefore, in the process of active cognitive work, a person has the opportunity to radically change the ethno cultural image of the world using language. Thanks to the language, ethno cultural painting is transmitted from generation to generation and helps to preserve elements that contribute to the further development of society. As a socio-cultural factor, language strengthens and reproduces the values that shape, organize and transfer experience to the next generation. As a speaker of culture and language, man perceives the world in accordance with his experience and worldview and on its basis forms his ideas 
about the surrounding reality (Smokotin, 2011).

The concepts and meanings used by people in the process of conversation absorb and bear the peculiarities of national culture and language. Such features contribute to the preservation of the national mentality. This situation can be seen in the language of everyday, normal communication, which contributes to the formation of national identity, the development of the logic of ethnicity, the ethno cultural image of the world. In turn, this situation contributes to the preservation of ethno cultural identity. The language preserves the history of the movement and activity of people towards civilization, reflects the character of the population and its relations with other neighboring peoples. The language absorbs the evaluation ratio of the subject to reality. The first methods of verbal communication are formed on the basis of the native language. Usually this is the language of mother, grandmother, family; with its help the socialization of the individual is realized, the values, norms and values of his ethnic group are recognized. In the early stages of ethnic history, language played a key role in the formation of ethno cultural identity (Smokotin, 2011).

The sociocultural experience of generations, the attitude to the conditions of the natural and social environment reflected in the language, not only affects the perception of the world by the individual, but also forms a linguistic picture of the world based on ethno cultural experience. Although the phenomena of objective reality are the same for all ethnic groups, each ethnos understands and evaluates them in different ways. These differences are written in words. Language is considered the carrier of cultural values of ethnic group, the regulator of public relations. In this case, the language is ethno-culturally identifiable.

Thus, the language semantically (using vocabulary) embodies various cultures of this ethnic group, and also creates and maintains a linguistic picture of the world. In addition to the above, language performs two main functions as the main feature of ethnos: the first language serves as an ethno differentiating feature for "others" and a factor of ethnic integration for "one's own." Therefore, this is a means of separating "one's" from "others" and ensuring the self-preservation of the ethnic group. The language develops common meanings used by all subjects as a means of communication. The possibility of communication unites members of an ethnic group.

Language as the main means of communication between people means not only mastering the linguistic code, but also allows us to study the accumulated fund of cultural experience. Learning language means understanding its phonetic, syntactic, semantic and pragmatic rules (Smokotin, 2011).

At the end of the twentieth century, scientific literature was divided on the role of language as an ethnic symbol. At first glance, language is considered as an optional sign of ethnic community. According to the second view, ethnic identity belongs to a certain people and is determined only by the language he created. Proponents of this point of view argued that different peoples have a common language. In this case, each ethnic group introduces certain features into its own version of the language. 
In the context of globalization, independent systems in the information space of civilization are growing, in which case language, despite its dynamism, functions as the main means of preserving ethnic identity. Language reflects objective reality through a system of spiritual skill.

In communication, a direct connection between language and culture is obvious. Language is not only a means of communication, but also a powerful social tool that conveys culture and traditions to the next generation, uniting peoples into ethnic groups through the formation of social consciousness, forming a nation (Humboldt, 1964).

Language as the main characteristic of ethnos performs two main functions. It develops generally accepted meanings as a means of preserving the ethnic group and distinguishing it from others, which is the result of its historical, cultural, economic and industrial activities.

Each word in the ethno-language enhances the diversity of ethnic ties and relationships with the real world. The semantic, cultural and linguistic completeness of the ethnolinguistic structure in comparison with the languages of other ethnic groups depends on the presence or absence of similar objects and phenomena in the practice of material and spiritual activity, the background of the lifestyle, stereotypes of behavior, natural and geographical living conditions depending on historical and cultural traditions.

From a cultural and communicative point of view, language reinforces the features and distinctive features of the ethnic image of the world, the foundations of ethnocultural identity as a result of language.

The ethnic image of the world is a set of ethno-social ideas; within the framework of which the ethnos, its history and culture function (Serebrennikov, 1988). These perceptions are universal for each member of an ethnic group and are characterized by stability, intergenerational transmission and the coercive nature of influence. The system of ethno social representations, enshrined in the language, is the core of ethnic identity, determines the behavioral program of the ethnos, the dominant prerequisite for interaction.

The main features and characteristics of the ethnic image of the world are enshrined in the language as a mechanism for determining the nature of ethnic culture. As a result, the historical memory of the people is preserved, ethnocultural experience is transmitted from generation to generation, norms of behavior reflected in language, and lifestyle features are determined.

Thus, all the main features and characteristics of the ethnic image of the world are enshrined in a language known as the mechanism for restoring the main features of ethnic culture. As a result, the historical memory of the people is preserved and the ethnocultural experience of generations is transferred. Language is the bearer of ethno social representations. The communicative space of each ethnic group is formed in the process of historical and cultural development of the lexical composition and content and these features play an important role in maintaining the integrity of society and sociocultural transformation. 


\section{The English Language-Ethno Cultures}

In today's objective reality, global socio-economic processes and media in the context of the dissemination of English not only change the external aspects of culture around the world, but also reduce the number of national languages, limiting their meaning and content.

Due to the universal nature of the world economy, this language, which many understand more or less, will become the basis of international relations, as well as trade with other countries. This situation is gradually pushing back the languages of national minorities. In addition, developing modern technology strives to combine languages into a single standard.

Public education policies also have a significant impact on reducing the number of languages. Not only in developed countries, but also in developing countries students study in English at many universities and colleges to keep up with science and technology. The number of such schools is constantly growing, which creates conditions for a profound change in the type of thinking, as well as mentality.

The spread of English not only creates similar structures in the economy and politics of different countries, but also tries to adapt Western culture to local conditions, local customs and ethnoculture. In this case, the territorial forms of human activity are of a different nature. Globalization also provides opportunities for local cultures and values to learn and learn from, and preserve, the new experiences of other civilizations.

The language of each person is his real consciousness, fully reflecting the various spheres of social life. Each new generation, representative of a certain ethnic group, through mastery of language joins the historically known system of social relations, acquires collective experience, knowledge of reality, generally accepted rules of behavior, sociocultural values. The language reflects the cognitive experience of people, their moral and ethical, socio-aesthetic, artistic and educational ideas. The language preserves the history of the civilized development of the people.

It determines the national character, relations with other people and peoples, patterns of behavior. The language reflects the peculiarities of ethnic attitude to the environment, perception of reality in the system of values, motives of behavior. Therefore, language plays a special role in the formation of ethnocultural identity in the process of social development. The socio-cultural experience of the ethnic group is presented in different linguistic forms. The language reflects the history of the movement of people towards civilization, their relationship with other peoples (Humboldt, 1964).

Current sociolinguistic studies show that in the future, only five languages are expected to function as the main languages of international communication on the planet. They include English, Russian, Chinese, Spanish and Arabic. Complete globalization requires a single language or language that combines the languages listed above. 
The value picture of the world includes universal and ethnic characteristics. The dominant value reflected in it is supported by the language and forms a certain cultural type. For example, the main values of English speakers are: rationality, independence, equality, individuality, pragmatism, competition, tolerance, emotional self-control, and so on.

The objects of a positive assessment of the world are: freedom, independence, autonomy, distance, non-interference in other people's affairs, confidentiality, and so on. These characteristics are positively perceived by non-English speaking peoples and developed countries with a high degree of urbanization. By spreading their language, Anglo-Saxon peoples sought to spread their value system around the world and assimilate it among other peoples and ethnic groups.

Value systems of different linguistic cultures differ from each other in ethnic characteristics. It is expressed in a language in a context that provides communicative activity for members of the ethnocultural community and refers to communicative consciousness. These values have a significant impact on the communicative behavior of the population and the formation of a national style of communication. Thus, the transition of society from one native language to another means a perception of the behavior of other peoples, the formation of a different system of ethno communication.

The rapidly increasing mobility of people and the rapid growth of information also lead to cultural similarities, unilateralism and language loss among a small number of peoples around the world. The economy and the media are changing the face of global culture in the context of globalization. Due to the multifaceted nature of the world economy, universal language will become a pillar of the trade and dissemination of the English language. Over time, this situation gradually crowds out the languages of national minorities. In addition, it seeks to bring telecommunications, media and the Internet to a common standard.

The terms of trade and the spread of mass culture make people learn the most common languages in the world. If you do not speak such a language, certain business difficulties, such as obstacles to access to information, negatively affect the overall development of the subject (Fedotova, 2000).

With language relations and transformations another related factor is mass migration and the formation of ethnic enclaves, in which case you can quickly move to a state of bilingualism.

\section{Global Identity}

In the European humanities, debate about the nature of language in the postethnic world, which is closely related to the controversy surrounding the concept of the nation, is well underway. English is seen as a natural process reflecting the new global identity of those who hold positive views. English product names and advertising strategies are a global aesthetics, a global value system. They are strengthened in normal life, and a new system of beliefs and social behaviors is being created. The result is not the linguistic influence of the British, but the 
emergence of a globalized elite. Behind this phenomenon is the ideology of global monopolies, in which the free movement of people and capital is important. National borders and territories, like national languages, negatively affect globalization. In this case, the language is considered only as a means of transmitting information, a set of characters.

According to the famous Russian philosopher S. Panarin, globalization is known as "the process of removing traditional regional socio-cultural and state-political barriers, a new system of international relations and interdependence" (Panarin, 2000).

One of the main characteristics of modern objective reality is the globalization of cultures. This process includes cultural contradictions and conflicts. At the same time, language processes inevitably have some contradictions. In other words, conflicts and differences between different civilizations and cultures are one of the main factors of the modern socio-cultural situation. In today's geopolitical space, the peoples of the world, civilization, nation and state are trying to change their history and identity. In other words, the protection of national, ethnic and local traditions, the preservation and revival of ethnic language characteristics are becoming a global phenomenon. However, globalization, including the spread of English, had led to the decline of national languages.

The international status of the English language and its spread throughout the world allow Western culture to dominate almost all other cultures. At the same time, English expands and reduces minority languages. To get out of this situation, these cultures must adopt a massive Western culture. This situation, in other words, the assimilation of Western culture limits the independence of national cultures. As a result, over time, the cultural values of the ethnic group collapse and the problem of cultural isolation arises. The concepts of integration, disintegration, globalization and regionalization must be combined with those of local and global, traditional and liberal, democratic values, and must be carefully studied in the analysis of cultural values. In this regard, the application of ethnocultural values in life, their reconstruction will help solve the most pressing problems facing society.

Language plays a key role in shaping political, cultural and ethnic consciousness. When it is necessary to strengthen the unity of the community, they need to use a language understandable to the community. In various historical contexts, he characterizes ethnic identity in culture as a form of expression of community. In today's geopolitical space, the dominant forces in global development impede the integration of these ideas (Beck, 2008). This approach leads to terms such as "global identity." The creation of global identity reflects the emergence of metroethnicity. We can emphasize the path of globalization created by objective, natural and artificial, political and economic conditions, as well as by ideology. In today's socio cultural reality, there is a process of transition from a national culture to a global culture whose language is English. Western mass culture covers all areas of our lives, and the model of a liberal democratic society is 
being introduced in many countries. A new information space is being created (the Internet and other new information and communication technologies), and Western culture is globalizing. Time and space are approaching, and a new reality arises-a virtual world and a virtual person. Anti-globalists and opponents of Western culture are growing, and in such a socio-cultural situation, the problem of preserving the linguistic and cultural identity, the identity of the culture of other peoples becomes one of the most urgent. In integrating national culture into the world cultural space, it is important to preserve ethnic identity and language (Bartminsky, 2005). At the same time, it is necessary not only to isolate yourself from your culture and language, but also to join the world cultural space and keep pace with scientific, technical, technological and intellectual development. The idea of recognizing ethnic and national culture on a global scale is also wrong. It is always of valuable and great educational value, since it contains the axiological norms of a particular nation or ethnic group. National culture, like ethnolinguistic values, is the source of the formation of universal human spiritual heritage and values. It serves as a special basis for a worldview (Safiullina, 2004).

\section{Conclusion}

Globalization has reinforced the tendency of national cultures to lose their selfesteem. Countries that begin to lose their national values and foundations, along with the ideology of a market economy, adopt liberal values and bear many losses.

Therefore, in such a socio-cultural situation, each country must correctly assess its capabilities, determine its place in the process of globalization and choose the path to the future. At the same time, it should not be about the same economy or policy, but about ideology, a system of values, the preservation of civil peace and mutual understanding in a dynamic, unstable world, mutual agreement. Globalization demands a new way of communication in order to reach competence in the process of intercultural interaction. Finally, aligning the interaction requires individuals to foster the ability of intercultural adroitness, by which they can function effectively and appropriately in the global communication environment without violating their counterparts' norms and rules in order to reach a global civic society (Chen, 2005). As Former Secretary-General of the United Nation Kofi Annan said: "People of different religions and cultures live side by side in almost every part of the world, and most of us have overlapping identities which unite us with very different groups. We can love what we are, without hating what-and who-we are not. We can thrive in our own tradition, even as we learn from others, and come to respect their teachings."

\section{Conflicts of Interest}

The authors declare no conflicts of interest regarding the publication of this paper. 


\section{References}

Agaev, A. G. (1968). Functions of Language as an Ethnic Characteristic. In Languages and Society (pp. 124-138). Moscow: Nauka.

Akmoldoeva, Sh. B. (1998). The Spiritual World of the Ancient Kyrgyz (Based on the Materials of the Manas Epic). Bishkek: Ilim.

Bartminsky, E. (2005). The Linguistic Image of the World: Essays on Ethnolinguistics (p. 512). M.: Indrik.

Beck, W. (2008). Cosmopolitan Worldview (p. 336). M.: Center for Research. Postindustr. Issue.

Chen, G.-M. (2005). A Model of Global Communication Competence. China Media Research, 1, 3-11. https://doi.org/10.1177/174276650500100103

Combi, M. (2016). Cultures and Technology: An Analysis of Some of the Changes in Progress-Digital, Global and Local Culture. In K. Borowiecki, N. Forbes, \& A. Fresa (Eds.), Cultural Heritage in a Changing World (pp. 3-15). Cham: Springer. https://doi.org/10.1007/978-3-319-29544-2 1

Crystal, D. (2004). The Past, Present, and Future of World English. In A. Gardt, \& B. Hüppauf (Eds.), Globalization and the Future of German (pp. 27-45). Berlin: De Gruyter.

Fedotova, N. N. (2000). Is World Culture Possible? Philosophy Sciences, 4, 58-68.

Humboldt, V. (1964). On the Comparative Study of Languages in Relation to Various Eras of Their Development. In V. A. Zvegintsev (Ed.), History of Linguistics of the XIX and XX Centuries Part 1 (pp. 73-84). Moscow: Progress.

Kozlov, M. (1994a). Philosophical Works. Part 1 (p. 612). M.: Gnosis.

Kozlov, M. (1994b). Philosophical Works. Part 2 (p. 208). M.: Gnosis.

Panarin, S. A. (2000). Political Science (p. 480). M.: Gardariki.

Safiullina, I. M. (2004). Language in the Communicative Space of Ethnic Groups (p. 176).

Scannavini, K. (2013). The Necessity of Intercultural Communication for a Peaceful World. Academicus: International Scientific Journal, 8, 172-188.

https://doi.org/10.7336/academicus.2013.08.11

Serebrennikov, B. A. (1988). The Role of the Human Factor in Language: Language and Picture of the World (p. 212). M.: Science.

Smokotin, V. M. (2011). Language of World Communication and Ethnocultural Identity: Complementarity in the Context of Globalization (p. 34).

Xue, J., \& Zuo, W. J. (2013). English Dominance and Its Influence on International Communication. Theory and Practice in Language Studies, 3, 2262-2266. https://doi.org/10.4304/tpls.3.12.2262-2266

Ysmailova, R. A., Kochkonbaeva, S. I., \& Zhakaeva, G. K. (2020). The Essence of Language in the Context of Globalization. Interactive Science, 7, 76-79.

https://doi.org/10.21661/r-551630 